\title{
Work Personality and Decision Making Styles among Working and Non-Working Students
}

\author{
Raymond Doe, Matthew S. Castillo, Andrené B. McKinney \\ Department of Psychology, Lamar University, Beaumont, Texas, USA \\ Email: rdoe@lamar.edu, mcastillo21@lamar.edu, amckinney2@lamar.edu
}

How to cite this paper: Doe, R., Castillo, M.S. and McKinney, A.B. (2017) Work Personality and Decision Making Styles among Working and Non-Working Students. Open Journal of Social Sciences, 5, 286-297. https://doi.org/10.4236/jss.2017.56024

Received: March 2, 2017

Accepted: June 27, 2017

Published: June 30, 2017

\begin{abstract}
This study investigated adaptive decision making styles (DMSs; Rational and Intuitive) among working and non-working students. These cognitive styles involve approaching tasks objectively, analytically, thoroughly and unemotionally. Workers performing tasks in organizations are expected to use intuition and make rational business decisions compared to non-workers. Work personality, which is influenced by both home and school environments, has been identified to influence critical adult work behaviors such as task completion as well as how we engage with others in work settings. Increasingly, college aged students are working full or part-time and have to combine their studies with work demands in addition to other responsibilities at home. Prior studies have found no significant differences between working and nonworking students on outcomes such as academics and social experiences. However, working students seem to transfer and optimize their decision making competencies to be successful on the job and in college compared to non- working students. We predicted that task oriented working students would use more adaptive decision making styles than non-workers after controlling for gender and age. A total of 130 respondents participated in this study and the results partially supported our assertion. Task oriented working students were significantly different than non-working students in the use of the rational decision making style than any other DMS. Our results were consistent with previous studies on adaptive decision making styles.
\end{abstract}

\section{Keywords}

Work Personality, Decision Making, Workers, Students

\section{Introduction}

With the price of a college education on the continual rise, part time or full time 
employment has become a requirement instead of a choice for most students enrolled at universities across the nation [1]. In 2007, an estimated 45 percent of college students were working full time and around 80 percent were working part time [2]. Since this data was collected almost a decade ago, it is not a far jump to conclude that these numbers have increased over time.

According to Yum, Kember, and Siaw [3], working students generally interact with four domains. These domains are self, work, family, and social life. While the ideal situation would be to have equal amounts of each domain, students often find that one or two domains tend to take up the majority of their time. Within the self domain, working students have to sacrifice money and time in order to find a balance between their work and school life [4]. The social life domain also has a tendency to suffer from the work/study domain. Students who work full or part time find it easier to decline social outings with their friends which have been linked to higher levels of depression in some students [5]. For working students, the work domain encompasses the majority of their time. Employers are often callus to the time related needs of their employees, and often require their employees to have open availability. Because of this, some working students have a tendency to miss lectures or studying to work [4].

Individuals spend a considerable amount of time at work. According to a survey conducted by the Bureau of Labor Statistics [6], the average employed American works around 7.6 hours a day. With the amount of time employees spend at work, it is believed that their motivation and behavior within the workplace must stem from some internal operations. While it is already known that differences exist across individuals' personalities in everyday life, differences also exist in their personalities towards work. Researchers have found that individual differences play a substantial role in an employee's motivation to work as well as their behavior towards the job, co-workers and overall workplace environment [7].

\section{Review of Literature and Theoretical Framework}

A useful theoretical framework that describes the role of personality and its relationship and interaction with individual's motivation processes and work performance is the Theory of Purposeful Work Behavior [7]. The core of purposeful work behavior is based on the five factor model of personality; it explains the interaction of traits and job characteristics and how they influence work outcomes. These work outcomes are preceded by decision making processes. The result, whether adaptive or not, has varying consequences for the individual and overall life success. Although trait theories of personality have provided adequate explanation of individual differences, there is limited amount of research on work personality and decision making styles among working and non-working students.

The concept of work personality stems from the research conducted on Social Learning Theory by Bandura [8] [9], Neff's ideas on workplace personality [10], and Erikson's Developmental Stage Theory [11]. Combined, these theories and 
ideas helped mold the foundation of work personality by focusing on school and home environments as well as the role models that are influential in grade school [12]. There are two primary domains that are said to be experienced while in grade school: completion of home and school tasks, and interpersonal and social skills of relating to peers and figures of authority. It is believed that these behavioral domains lay the groundwork for task completion and social skills that are critical in adult work behavior [12] [13].

If a child experiences a lack of positive role models, or an impoverished environment, then the behavioral domains mentioned above might not have a chance to fully blossom due to the lack of opportunities that would be afforded them [12]. Children with disabilities are also at risk of not developing in these domains as a result of spending most of their childhood navigating the ends and outs of their disability while missing out on key social situations and relationships [14] [15]. Research on task completion and social skills has focused mainly on individuals in work settings, team based activities and educational settings. These contexts require individuals to make decisions, usually involving others, and produce a desirable outcome.

Decision making styles (DMSs) are defined as a response pattern that over time becomes habitual to an individual and is exhibited when the individual is confronted with a situation that requires a decision [16]. Throughout all of the research that has been conducted, nine decision making styles have been found [17] [18]. However, only five have been studied closely; the rational, the intuitive, the dependent, the avoidant, and the spontaneous DMS [16]. The rational decision making style is manifested in a constant comprehensive search of information. People who use this style tend to always have alternatives that they logically evaluate before making any decision. The intuitive decision making style is characterized by painstaking attention to details. People with this style pay extremely close attention to the information that they are receiving rather than seeking out and then processing information. They also have a tendency to pay more attention to their feelings and premonitions. Both the rational and the intuitive decision making styles are linked to more positive outcomes and, out of the five, are considered the most adaptive [18] [19] [20]. The dependent decision making style is portrayed as a person who is always asking for advice and guidance from peers or authority figures before they can make any important decision. Those using the avoidant decision making style tend to avoid the decision making process altogether. Finally, those using the spontaneous decision making style make decisions instantaneously and without much thought [16]. These three styles are often looked at as non-adaptive and thus not greatly desired within individuals [21]. Workers with task oriented personality are therefore expected to demonstrate adaptive decision making styles than non-workers. We propose that, controlling for gender and age;

1. Task oriented workers will use the Rational DMS more than non-workers.

2. Task oriented workers will use the Intuitive DMS more than non-workers.

3. Task oriented workers will use the Spontaneous DMS less than non-workers. 
4. Task oriented workers will use the Avoidant DMS less than non-workers.

\section{Method}

\subsection{Participants}

A total of 130 undergraduate students at a medium sized university in the Southeastern region of the United States took part in this study by signing up via the online SONA system after Institutional Review Board (IRB) approval \#7341725. These participants ranged in age from 18 to 44 where the median age was 19 and the average age was 20 . The majority of respondents were women $(77.7 \% ; n=$ 101). A total of $40.8 \%$ of the students were sophomores $(n=53), 33.1 \%$ were freshman $(n=43), 16.2 \%$ were juniors $(n=21)$, and $10.0 \%$ were seniors $(n=$ 13). Participants self-reported their working status revealing $63.8 \%$ were workers $(n=83)$ and $36.2 \%$ were not workers $(n=47)$. Students received research credits for their participation.

\subsection{Materials}

A survey was given to participants consisting of a 14-item revised work personality scale based on the Developmental Work Personality Scale (DWPS) [22], the General Decision Making Style Questionnaire (GDMS) [16], and demographic items capturing participants' gender, age, student classification, and work status (working or not working). The original DWPS is "a 26 -item selfreport measure addressing behaviors, role models, and tasks that individuals encounter during middle childhood" (p. 274) [12]. The revised version contains three subscales with items pertaining to work tasks, role models, and social skills. Respondents reflect on their experiences in childhood and rate items on a scale ranging from 0 (Not at all like me) to 5 (Very much like me). A previous factor analysis revealed adequate internal consistency reliability of each subscale ranging from 0.75 to 0.90 . The GDMS measures rational, intuitive, dependent, avoidant and spontaneous decision making styles and consists of 5 items per dimension for a total of 25 items [16]. Respondents reflect on the way they make decisions and rate items on a scale ranging from 1 (Strongly disagree) to 5 (Strongly agree). Previous studies reveal alpha coefficients above 0.71 for each subscale [16] [20] [23].

\subsection{Procedure}

Participants came to the research lab at their designated time and were given an informed consent form to read over and sign. This document explained that participants were taking part in a study assessing characteristics of workers and non-workers. Once a participant indicated that he or she agreed to take part in the study, they were given the survey instrument to fill out. Upon completion, the participant returned the survey to the researchers and was shown out of the research lab. Data was entered into the statistical software SPSS and screened to identify and remove outliers. 


\section{Results}

Descriptive statistics were used to compare gender and age across workers and non-workers. For workers $(n=83), 75.9 \%$ of respondents were women $(n=63)$ and $24.1 \%$ were men $(n=20)$. Ages for workers ranged from 18 to 31 where the median age was 20 and the average age was also 20 . For non-workers $(n=47)$, $80.9 \%$ of respondents were women $(n=38)$ and $19.1 \%$ were men $(n=9)$. Ages of non-workers ranged from 18 to 44 where the median age was 19 and the average age was 20 .

Hierarchical multiple regression analyses were conducted for each of the five decision making styles (DMSs) across workers and non-workers using the DMS as the dependent variable and the three work personality subscales (work tasks, role models, social skills), age, and gender as the independent variables.

\subsection{Working Students}

A correlation matrix of the variables for working students is presented in Table 1. The structural (demographic) variables gender and age were entered simultaneously in stage one of the regression analyses. The work personality subscales (work tasks, role models, social skills) were entered in stage two. The correlations between the work personality subscales and the decision making styles were low and were mostly not statistically significant except work tasks with the rational decision making style $(r=0.59, p=0.000)$. The intuitive decision making style did not correlate highly with the work personality subscales (see Table 1).

The results presented in Table 2 shows the five hierarchical multiple regression analyses with each decision making style as the dependent variable. When the two control predictors (gender and age) were entered simultaneously in Step 1 , the models explained small amounts of variance in all the decision making styles and were not significant. After the entry of the work personality subscales (work tasks, role models, and social skills) in Step 2, the models explained an

Table 1. Means, standard deviations and correlations among study variables workers $(\mathrm{N}=83)$.

\begin{tabular}{|c|c|c|c|c|c|c|c|c|c|c|c|c|}
\hline & M & SD & 1 & 2 & 3 & 4 & 5 & 6 & 7 & 8 & 9 & 10 \\
\hline \multicolumn{13}{|l|}{ 1. Gender } \\
\hline 2. Age & 20.73 & 2.96 & -0.08 & & & & & & & & & \\
\hline 3. Work Tasks & 29.20 & 4.50 & -0.02 & -0.01 & & & & & & & & \\
\hline 4. Role Model & 11.82 & 3.30 & 0.06 & 0.04 & 0.42 & & & & & & & \\
\hline 5. Social Skills & 2.19 & 3.31 & -0.06 & -0.06 & -0.25 & -0.23 & & & & & & \\
\hline 6. Rational & 22.12 & 2.90 & 0.14 & 0.04 & $0.59^{\star * *}$ & $0.30^{\star *}$ & $-0.31^{\star *}$ & & & & & \\
\hline 7. Intuitive & 18.66 & 3.68 & 0.08 & -0.07 & 0.03 & 0.05 & 0.06 & -0.04 & & & & \\
\hline 8. Dependent & 16.78 & 4.77 & 0.04 & -0.03 & 0.20 & 0.13 & -0.10 & 0.12 & 0.18 & & & \\
\hline 9. Avoidant & 12.43 & 5.60 & 0.02 & -0.04 & -0.11 & -0.09 & 0.07 & $-0.34^{\star *}$ & 0.19 & $0.33^{\star *}$ & & \\
\hline 10. Spontaneous & 12.30 & 4.60 & -0.08 & 0.01 & 0.06 & -0.03 & 0.19 & -0.21 & $0.25^{\star}$ & 0.14 & $0.42^{\star * *}$ & \\
\hline
\end{tabular}

${ }^{\star} \mathrm{p}<0.05 ;{ }^{* *} \mathrm{p}<0.01 ;{ }^{* *} \mathrm{p}<0.001$. 
Table 2. Hierarchical multiple regression for decision making styles among workers.

\begin{tabular}{|c|c|c|c|c|c|c|c|c|c|c|}
\hline & \multicolumn{2}{|c|}{ Rational } & \multicolumn{2}{|c|}{ Intuitive } & \multicolumn{2}{|c|}{ Dependent } & \multicolumn{2}{|c|}{ Avoidant } & \multicolumn{2}{|c|}{ Spontaneous } \\
\hline & $\beta$ & $\Delta \mathrm{R}^{2}$ & $\beta$ & $\Delta \mathrm{R}^{2}$ & $\beta$ & $\Delta \mathrm{R}^{2}$ & $\beta$ & $\Delta \mathrm{R}^{2}$ & $\beta$ & $\Delta \mathrm{R}^{2}$ \\
\hline Step 1 & & 0.02 & & 0.01 & & 0.00 & & 0.00 & & 0.01 \\
\hline Gender & 0.15 & & 0.07 & & 0.04 & & 0.02 & & -0.08 & \\
\hline Age & 0.05 & & -0.06 & & -0.02 & & -0.04 & & 0.00 & \\
\hline Step 2 & & $0.37^{\star * *}$ & & 0.01 & & 0.04 & & 0.02 & & 0.05 \\
\hline Gender & 0.14 & & 0.08 & & 0.03 & & 0.02 & & -0.06 & \\
\hline Age & 0.04 & & -0.06 & & -0.03 & & -0.04 & & 0.02 & \\
\hline Work Tasks & $0.54^{* * *}$ & & 0.03 & & 0.16 & & -0.08 & & 0.12 & \\
\hline Role Model & 0.03 & & 0.06 & & 0.05 & & -0.05 & & -0.03 & \\
\hline Social Skills & -0.16 & & 0.08 & & -0.05 & & 0.04 & & 0.21 & \\
\hline Total $\mathrm{R}^{2}$ & & 0.39 & & 0.02 & & 0.04 & & 0.02 & & 0.06 \\
\hline
\end{tabular}

${ }^{*} \mathrm{p}<0.05 ;{ }^{* *} \mathrm{p}<0.01 ;{ }^{* * *} \mathrm{p}<0.001$.

additional $1 \%-37 \%$ of variance in the DMSs over and above gender and age. The work personality subscale work tasks was the only statistically significant predictor indicating a moderate positive relationship $(\beta=0.54, p=0.000)$ with the rational decision making style. No other beta values or models were significant (see Table 2).

\subsection{Nonworking Students}

Correlations among predictor variables for non-working students were examined and presented in Table 3. Results indicated low to moderate correlations and most did not reach the level of statistical significance. There was a significant correlation between the role models work personality subscale and the adaptive decision making styles (Rational and Intuitive) for non-working students $(r=0.488, p=0.001$ and $r=0.347, p=0.017$, respectively). Finally, the correlation was not significant for work tasks and the rational DMS was not significant but was significant for the intuitive DMS ( $r=0.43, p=0.002)$.

The regression models for non-working students showed mixed results. First, similar to the models for working students, the two control predictors explained small amounts of variance in all the decision making styles and were not significant. Second, after the entry of the work personality subscales (work tasks, role models, and social skills) in Step 2, the added variance explained by the models was $3 \%-25 \%$ over and above gender and age. This additional variance was only significant for the rational and intuitive DMSs. Among non-workers, the work personality subscale role models was statistically significant $(\beta=0.48, p=0.003)$ in predicting the rational decision making style. The subscale work tasks was also statistically significant $(\beta=0.32, p=0.042)$ in predicting the intuitive DMS but not the rational DMS. Finally, work tasks was significant $(\beta=0.35, p=$ 0.043 ) in predicting the spontaneous decision making style. No other beta values were significant (see Table 4). 
Table 3. Means, standard deviations and correlations among study variables-non-workers $(\mathrm{N}=47)$.

\begin{tabular}{|c|c|c|c|c|c|c|c|c|c|c|c|c|}
\hline & M & SD & 1 & 2 & 3 & 4 & 5 & 6 & 7 & 8 & 9 & 10 \\
\hline \multicolumn{13}{|l|}{ 1. Gender } \\
\hline 2. Age & 20.15 & 4.46 & 0.04 & & & & & & & & & \\
\hline 3. Work Tasks & 28.64 & 4.69 & 0.17 & 0.14 & & & & & & & & \\
\hline 4. Role Model & 11.02 & 3.59 & -0.04 & -0.23 & 0.33 & & & & & & & \\
\hline 5. Social Skills & 2.47 & 3.51 & $-0.45^{\star *}$ & 0.00 & -0.22 & 0.10 & & & & & & \\
\hline 6. Rational & 21.26 & 2.42 & -0.11 & -0.07 & 0.24 & $0.49^{\star *}$ & -0.01 & & & & & \\
\hline 7. Intuitive & 17.68 & 3.74 & 0.03 & 0.12 & $0.43^{\star *}$ & $0.35^{\star}$ & -0.04 & 0.21 & & & & \\
\hline 8. Dependent & 17.40 & 4.81 & 0.09 & -0.09 & -0.08 & -0.04 & -0.16 & 0.12 & 0.15 & & & \\
\hline 9. Avoidant & 11.68 & 5.09 & -0.09 & -0.10 & -0.25 & -0.21 & -0.15 & -0.07 & 0.16 & $0.38^{\star *}$ & & \\
\hline 10. Spontaneous & 12.04 & 4.18 & 0.01 & 0.11 & 0.27 & -0.07 & 0.01 & -0.10 & $0.48^{* *}$ & 0.15 & 0.09 & \\
\hline
\end{tabular}

${ }^{*} \mathrm{p}<0.05 ;{ }^{* *} \mathrm{p}<0.01 ;{ }^{* *} \mathrm{p}<0.001$.

Table 4. Hierarchical multiple regression for decision making styles among non-workers.

\begin{tabular}{|c|c|c|c|c|c|c|c|c|c|c|}
\hline & \multicolumn{2}{|c|}{ Rational } & \multicolumn{2}{|c|}{ Intuitive } & \multicolumn{2}{|c|}{ Dependent } & \multicolumn{2}{|c|}{ Avoidant } & \multicolumn{2}{|c|}{ Spontaneous } \\
\hline & $\beta$ & $\Delta \mathrm{R}^{2}$ & $\beta$ & $\Delta \mathrm{R}^{2}$ & $\beta$ & $\Delta \mathrm{R}^{2}$ & $\beta$ & $\Delta \mathrm{R}^{2}$ & $\beta$ & $\Delta \mathrm{R}^{2}$ \\
\hline Step 1 & & 0.01 & & 0.02 & & 0.02 & & 0.01 & & 0.01 \\
\hline Gender & -0.10 & & 0.03 & & 0.09 & & -0.08 & & 0.00 & \\
\hline Age & -0.06 & & 0.12 & & -0.10 & & -0.09 & & 0.11 & \\
\hline Step 2 & & $0.25^{\star}$ & & $0.23^{*}$ & & 0.03 & & 0.13 & & 0.10 \\
\hline Gender & -0.15 & & -0.02 & & 0.03 & & -0.16 & & -0.02 & \\
\hline Age & 0.04 & & 0.14 & & -0.08 & & -0.09 & & 0.02 & \\
\hline Work Tasks & 0.08 & & $0.32^{*}$ & & -0.11 & & -0.21 & & $0.35^{\star}$ & \\
\hline Role Model & $0.48^{\star *}$ & & 0.27 & & -0.01 & & -0.15 & & -0.19 & \\
\hline Social Skills & -0.11 & & -0.01 & & -0.17 & & -0.25 & & 0.09 & \\
\hline Total $\mathrm{R}^{2}$ & & 0.26 & & 0.25 & & 0.05 & & 0.14 & & 0.11 \\
\hline
\end{tabular}

${ }^{*} \mathrm{p}<0.05 ;{ }^{* *} \mathrm{p}<0.01 ;{ }^{* * *} \mathrm{p}<0.001$.

\section{Discussion}

The present study predicted that working students with task oriented personalities will demonstrate more adaptive decision making styles than non-workers after controlling for gender and age. Comparing working and non-working students, the results partially supported our hypotheses. Overall, higher work task personality scores tended to predict the rational DMS for working students compared to non-working students. However, this trend was not replicated for the intuitive DMS. Hypothesis one was therefore supported but not hypothesis two. These findings were consistent with previous studies [19] [23]. A few considerations must be mentioned that could have impacted our results.

First, labeling the rational and intuitive DMSs as adaptive-having an ability to change to suit-is still debatable in the literature. One argument is that both the 
rational and intuitive DMSs yield different results; for example, in relation to competence, innovativeness [16], and social desirability [23]. Previous research also shows that the intuitive DMS is positively associated with the spontaneous DMS [24]. Scott and Bruce [16] even concluded that the spontaneous DMS is just a high-speed intuitive DMS. In the present study, the correlations between the intuitive and spontaneous DMSs for working students and non-working students were positive and significant ( $r=.25$ and 0.48 , respectively); thus confirming previous assertions. The intuitive DMS could therefore be considered as less of an adaptive style. Epstein [25] noted that the concept of intuition has been operationally defined in so many ways that researchers wonder what the term even means. Currently, there are at least three different types of intuition in extant literature [26].

Secondly, studies using the big five personality traits tended to find unique and independent correlations with the rational and adaptive DMSs. Riaz, Riaz, and Batool [27] found that Extroversion and Openness to Experience positively predicted the intuitive DMS while Conscientiousness positively predicted the rational DMS. In addition, the current results showed that non-workers with work task personality positively predicted the intuitive DMS but not the rational DMS. Our findings, coupled with previous studies, show that there might be other factors apart from personality (such as emotional intelligence, creativity, or transformational leadership) that could help explain the differences in adaptive DMSs. For example, a study by Avsec [20] using working students showed that emotionally intelligent individuals use the intuitive DMS more frequently than any other style. Although a number of studies have reported that rational and intuitive DMSs have the most positive outcomes compared to other DMSs, prior evidence supports that labeling of adaptive and non-adaptive DMSs may need to be re-examined and explored further.

In addition, we predicted based on previous discussions on the adaptive and less-adaptive divide that working students with work task personality will use less spontaneous and avoidant DMSs than their non-working counterparts. In other words, non-working students who identify themselves with work task personality should make rapid and spontaneous decisions, postpone, or avoid making decisions all together. Our results supported hypothesis three but not four. That is, comparatively, work task personality among non-working students was significant $(\beta=0.35, p=0.043)$ in predicting the spontaneous decision making style compared to working students. The model as a whole, however, was not significant. These findings could indicate that even though non-working students engage in tasks either for academic purposes or non-academic activities, decisions made to fulfill these tasks tend to be carried out spontaneously. It is also important to include that the correlations with the avoidant DMS were negative, implying that tasks among non-working students are not being avoided.

Currently, it is difficult to find a conceptual model for avoidant, dependent and spontaneous DMSs, and it is too early to categorize these as non-adaptive. 
Regardless, there are some results indicating that avoidant and dependent DMSs are positively associated with depressive tendencies [18], and avoidant and spontaneous DMSs are negatively associated with life satisfaction [28]. There may be other factors beyond personality that affect the decision making of both non-working students and working students.

\subsection{Conclusions}

The role of personality in predicting work related outcomes has been extensively covered in the literature [29] [30] [31] [32]. Some of the key conclusions of these studies have informed us that the relationship between personality and any performance variable depends on the big five traits, but they are still valuable predictors. Apart from the question of personality trait validity, there is a growing trend to understand the influence of personality traits shaped by home and school environments on organizational behavior throughout individuals working lives from elementary to college years [12] [33]. Based on the present study, it seems that work personality does influence the efficiency of tasks and decision making. We assert that performance of work related tasks can be carried to academic contexts.

One of the key implications of this study is that students with adaptive decision making styles have a tendency to make better decisions throughout their time as students and beyond. While not all students are employed, this study shows that working students with adaptive decision making styles not only have a tendency to perform better in the classroom, but in their work setting as well. Wong, O'Sullivan, and Strauser [12] found in their study that kids who experienced positive role models and a stable environment growing up had better outcomes when it came to task completion and social skills. It is believed that personality is not constant but prone to change over time [34]. Looking ahead, it may be beneficial to learn about different decision making styles in hopes of modeling more adaptive decision making styles for the future generations.

\subsection{Limitations and Recommendations}

There are some limitations to these findings. First, the present study used a sample from a college student population who volunteered to take part for research participation credit; results may be different from non-college adults or the population of workers. Future studies should attempt to replicate the present findings in an organizational setting to compare work personality and decision making styles of current employees to working and non-working students. Another concern is the small sample size used. Subsequent research attempting to replicate our findings should include a larger number of participants. In addition, self-report measures in the form of questionnaires were used to capture work personalities and decision making styles across working and nonworking students. Although self-report measures are generally considered accurate, there is the potential for individuals to fake or inflate their work personality or decision making styles [35]. A future study should consider using a different method 
such as behavioral measures to objectively assess decision making styles in both academic and organizational settings. Despite these limitations, it is hoped that this study has provided useful comparison of working and non-working students in academic institutions which will help and improve our knowledge of the work personality and decision making styles of students.

\section{References}

[1] Choy, S. and Berker, A. (2003) How Families of Low-and Middle-Income Undergraduates Pay for College: Full-Time Dependent Students in 1999-00 (NCES 2003-162). U.S. Department of Education, National Center for Education Statistics, Washington DC.

[2] Perna, L.W. (2010) Understanding the Working College Student. https://www.aaup.org/article/understanding-working-college-student\#.WKPL7VMr $\underline{\mathrm{LmF}}$

[3] Yum, J.C.K., Kember, D. and Siaw, I. (2005) Coping Mechanisms of Part-Time Students. International Journal of Lifelong Education, 24, 303-317. https://doi.org/10.1080/02601370500169194

[4] Mounsey, R., Vandehey, M.A. and Diekhoff, G.M. (2013) Working and NonWorking University Students: Anxiety, Depression, and Grade Point Average. College Student Journal, 47, 379-389.

[5] Mikolajczyk, R.T., Maxwell, A.E., Naydenova, V., Meier, S. and El Ansari, W. (2008) Depressive Symptoms and Perceived Burdens Related to Being a Student: Survey in Three European Countries. Clinical Practice and Epidemiology in Mental Health, 4, 19. https://doi.org/10.1186/1745-0179-4-19

[6] Bureau of Labor Statistics (2015) The Employment Situation-December 2015. https://www.bls.gov/news.release/archives/empsit 01082016.pdf

[7] Barrick, M.R., Mount, M.K. and Li, N. (2013) The Theory of Purposeful Work Behavior: The Role of Personality, Higher-Order Goals, and Job Characteristics. The Academy of Management Review, 38, 132-153. https://doi.org/10.5465/amr.2010.0479

[8] Bandura, A. (1986) Social Foundations of Thought and Action: A Social Cognitive Theory. Englewood Cliffs, Prentice-Hall, New Jersey.

[9] Bandura, A. (1989) Social Cognitive Theory. Annals of Child Development, 6, 1-60. https://pdfs.semanticscholar.org/e54f/2089df241007cb724693384d777613308505.pdf

[10] Neff, W.S. (1986) Work and Human Behavior. 3rd Edition, Aldine de Gruyter, New York.

[11] Erikson, E.H. (1968) Identity: Youth and Crisis. W.W. Norton, New York.

[12] Wong, A., O’Sullivan, D. and Strauser, D. (2012) Confirmatory Factor Analytical Study of the Revised Developmental Work Personality Scale. Assessment, Development, and Validation, 45, 270-291. https://doi.org/10.1177/0748175612449628

[13] O’Sullivan, D. and Strauser, D.R. (2010) Validation of the Developmental Work Personality Model and Scale. Rehabilitation Counseling Bulletin, 54, 46-56. https://doi.org/10.1177/0034355210378045

[14] Spelten, E.R., Sprangers, M.A.G. and Verbeek, J.H.A.M. (2002) Factors Reported to Influence the Return to Work of Cancer Survivors: A Literature Review. Psycho-Oncology, 11, 124-131. https://doi.org/10.1002/pon.585

[15] Taskila, T. and Lindbohm, M.L. (2007). Factors Affecting Cancer Survivors' Employment and Work Ability. ActaOncologica, 46, 446-451. 
https://doi.org/10.1080/02841860701355048

[16] Scott, S.G. and Bruce, R.A. (1995). Decision-Making Style: The Development and Assessment of a New Measure. Educational and Psychological Measurement, 55, 818-831. https://doi.org/10.1177/0013164495055005017

[17] Betsch, C. (2004). Preference for Intuition and Deliberation (PID): An Inventory for Assessing Affect- and Cognition-Based Decision-Making. Zeitschriftfür Differentielle und Diagnostische Psychologie, 25, 179-197. https://doi.org/10.1024/0170-1789.25.4.179

[18] Leykin Y. and DeRubeis, R.J. (2010) Decision-Making Styles and Depressive Symptomatology: Development of the Decision Styles Questionnaire. Judgment and Decision Making, 5, 506-515.

http://www.sjdm.org/ baron/journal/10/10119/jdm10119.pdf

[19] Bruine de Bruin, W., Parker, A.M. and Fischhoff, B. (2007). Individual Differences in Adult Decision-Making Competence. Journal of Personality and Social Psychology, 92, 938-956. https://doi.org/10.1037/0022-3514.92.5.938

[20] Avsec, A. (2012) Do Emotionally Intelligent Individuals Use More Adaptive Decision-Making Styles? StudiaPsychologica, 54, 209-220.

http://bwmeta1.element.cejsh-0a1012d8-34db-4d1a-a772-b810b78611a1

[21] Avsec, A., Novak, M. and Bajec, B. (2012) Differential Relationship of Coping Styles with Well-Being and Ill-Being of Professional Firemen. Psihologija, 45, 59-70. https://doi.org/10.2298/PSI1201059A

[22] Strauser, D.R. and Keim, J. (2002) Developmental Work Personality Scale: An Initial Analysis. Rehabilitation Counseling Bulletin, 45, 105-113. https://doi.org/10.1177/003435520204500205

[23] Thunholm, P. (2004) Decision-Making Style: Habit, Style, or Both? Personality and Individual Differences, 36, 931-944. https://doi.org/10.1016/S0191-8869(03)00162-4

[24] Loo, R. (2000) A Psychometric Evaluation of the General Decision Making Style Inventory. Personality and Individual Differences, 29, 895-905. https://doi.org/10.1016/S0191-8869(99)00241-X

[25] Epstein, S. (2008) Intuition from the Perspective of Cognitive-Experiential SelfTheory. In Plessner, H., Betsch, C. and Betsch, T., Eds., Intuition in Judgment and Decision Making, Erlbaum, New York, 23-37.

[26] Dane, E. and Pratt, M.G. (2009) Conceptualizing and Measuring Intuition: A Review of Recent Trends. In Hodgkinson, G.P. and Ford, J.K., Eds., International Review of Industrial and Organizational Psychology, Wiley, Chichester, 24, 1-40.

[27] Riaz, M.N., Riaz, M.A. and Batool, N. (2012). Personality Types as Predictors of Decision Making Styles. Journal of Behavioural Sciences, 22, 99-114.

http://pu.edu.pk/images/journal/doap/PDF-FILES/Abstract\%20no.\%208 Vol $22 \mathrm{~N}$ o 2 2012.pdf

[28] Deniz, M.E. (2006). The Relationships among Coping with Stress, Life Satisfaction, Decision Making Styles and Decision Self-Esteem: An Investigation on Turkish University Students. Social Behavior and Personality, 34, 1161-1170. https://doi.org/10.2224/sbp.2006.34.9.1161

[29] Barrick, M.R. and Mount, M.K. (1991) The Big Five Personality Dimensions and Job Performance: A Meta-Analysis. Personnel Psychology, 44, 1-26. https://doi.org/10.1111/j.1744-6570.1991.tb00688.x

[30] Barrick, M.R., Mount, M.K. and Judge, T.A. (2001) Personality and Performance at the Beginning of the New Millennium: What Do We Know and Where Do We Go Next? International Journal of Selection and Assessment, 9, 9-30. 
https://doi.org/10.1111/1468-2389.00160

[31] Barrick, M.R. and Mount, M.K. (2012) Nature and Use of Personality in Selection. In Schmitt, N., Ed., The Oxford Handbook of Personnel Assessment and Selection, Oxford University Press, Inc., New York, 225-251. https://doi.org/10.1093/oxfordhb/9780199732579.013.0011

[32] Hough, L. and Dilchert, S. (2010) Personality: Its Measurement and Validity for Employee Selection. In Farr, J.L. and Tippins, N.T., Eds., Handbook of Employee Selection, Taylor \& Francis Group, New York, 299-319.

[33] Woods, S.A., Lievens, F., De Fruyt, F. and Wille, B. (2013) Personality Across Working Life: The Longitudinal and Reciprocal Influences of Personality on Work. Journal of Organizational Behavior, 34, S7-S25. https://doi.org/10.1002/job.1863

[34] Murphy, L.B. (1989) There Is More Beyond: Selected Papers of Gardner Murphy. In Jefferson, Ed., McFarland \& Company, NC.

[35] Tourangeau, R., Rips, L. and Rasinksi, K. (2000) The Psychology of Survey Response. Cambridge University Press, Cambridge.

https://doi.org/10.1017/CBO9780511819322

\section{Scientific Research Publishing}

Submit or recommend next manuscript to SCIRP and we will provide best service for you:

Accepting pre-submission inquiries through Email, Facebook, LinkedIn, Twitter, etc. A wide selection of journals (inclusive of 9 subjects, more than 200 journals)

Providing 24-hour high-quality service

User-friendly online submission system

Fair and swift peer-review system

Efficient typesetting and proofreading procedure

Display of the result of downloads and visits, as well as the number of cited articles

Maximum dissemination of your research work

Submit your manuscript at: http://papersubmission.scirp.org/

Or contact jss@scirp.org 